\title{
P2X7 receptor and NLRP3 inflammasome activation in head and neck cancer
}

\author{
Ju Young Bae ${ }^{1, *}$, Sang-Woo Lee ${ }^{1, *}$, Yong-Hwan Shin ${ }^{1}$, Jong-Ho Lee ${ }^{2}$, Jeong Won Jahng ${ }^{3}$ \\ and Kyungpyo Park ${ }^{1, *}$ \\ ${ }^{1}$ Department of Physiology, School of Dentistry, Seoul National University, Seoul 110-749, Korea \\ ${ }^{2}$ Oral and Maxillofacial Surgery, School of Dentistry, Seoul National University, Seoul 110-749, Korea \\ ${ }^{3}$ Dental Research Institute, Seoul 110-749, Korea \\ "These authors contributed equally to this work
}

Correspondence to: Kyungpyo Park, email: kppark@snu.ac.kr

Keywords: purinergic receptor P2X7, NLRP3 inflammasome, head and neck squamous cell carcinoma, A253 cells, invasiveness Received: November 01, $2016 \quad$ Accepted: March 29, $2017 \quad$ Published: April 06, 2017

Copyright: Bae et al. This is an open-access article distributed under the terms of the Creative Commons Attribution License 3.0 (CC BY 3.0), which permits unrestricted use, distribution, and reproduction in any medium, provided the original author and source are credited.

\section{ABSTRACT}

In this study, we investigated purinergic receptor P2X7 and NACHT, LRR and PYD domains-containing protein 3 (NLRP3) inflammasome expressions, and their role in head and neck cancer. We found upregulation of purinergic receptor P2X7 and all NLRP3 inflammasome components in biopsied head and neck squamous cell carcinoma tissues. Similarly, the expression of purinergic receptor P2X7, apoptosis-associated speck-like protein containing CARD, and pro-form caspase 1 in A253 cells derived from epidermoid carcinoma were highly upregulated in comparison to normal Human Salivary Gland cell line. Active caspase-1 and its final product, active interleukin-1 $\beta$, both increased in primed A253 cells stimulated with purinergic receptor $\mathbf{P} 2 \times 7$ agonists, while this elevated NLRP3 inflammasome activity was suppressed by purinergic receptor P2X7 antagonists. However, we observed none of these effects in Human Salivary Gland cells. Inhibition of both NLRP3 inflammasome and purinergic receptor $\mathrm{P2X7}$ led to the significant cell death of primed A253 cells, but had no effect on the viability of primed HSG cells or the primary cultured human fibroblast cells. Furthermore, inhibition of either purinergic receptor P2X7 or NLRP3 inflammasome decreased invasiveness of A253, and this effect became more evident when both purinergic receptor P2X7 and NLRP3 inflammasome were simultaneously blocked. Therefore, it is concluded that the purinergic receptor P2X7 and the activation of NLRP3 inflammasome play important roles in the survival and invasiveness of head and neck squamous cell carcinoma in humans.

\section{INTRODUCTION}

The purinergic receptor $\mathrm{P} 2 \mathrm{X} 7$ ( $\mathrm{P} 2 \mathrm{X} 7 \mathrm{R})$, a member of the P2XR subfamily, is known to be triggered by ATP molecules to open its gate, mediating $\mathrm{Ca}^{2+}$ influx and $\mathrm{K}^{+}$ion efflux. Generally, P2X7R is known as a cytotoxic channel, since its sustained activation creates non-selective pores on cell membranes, leading to cell death [1]. However, recent studies have suggested the possibility that $\mathrm{P} 2 \mathrm{X} 7 \mathrm{R}$ facilitates the survival and invasion of tumor cells. For example, P2X7R-transfected cells showed increased growth activity and invasive activity both in vivo and in vitro [2]. Over expression of P2X7R has also been reported in various types of cancer, such as leukemia, neuroblastoma, melanoma, prostate, breast, and thyroid cancer [3-5]. Several mechanisms and pathways have been suggested to understand the functional roles of $\mathrm{P} 2 \mathrm{X} 7$ in cancer.

The NLRP3 inflammasome pathway is considered to be one of the most important P2XTR-induced downstream pathways [6]. According to previous studies, the NLRP3 inflammasome is assembled when ATP activates $\mathrm{P} 2 \mathrm{X} 7 \mathrm{R}$ to efflux $\mathrm{K}+$ ions [7]. NLRP3 inflammasome is a protein complex composed of NOD-like receptor protein 3 (NLRP3), apoptosis-associated speck-like protein containing a CARD (ASC), and caspase-1. Fully assembled NLRP3 inflammasome cleaves pro-form caspase-1(p45) into active caspase-1(p20), and the active 
caspase- 1 sequentially cleaves pro interleukin-1 $\beta$ (IL-1 $\beta$ ) into active IL-1 $\beta$, which is then released to extracellular space [7-9].

Previous studies have reported that either immune or non-immune cells under certain pathologic conditions such as Sjögren's syndrome [10], Bechet's disease [11], Type 2 diabetes [12], rheumatoid arthritis [13], and various types of cancers [2, 4, 14-18] show elevated expression of P2XR and/or NLRP3 inflammasome. Extensive studies have been conducted on P2XR and/or NLRP3 inflammasome in colon cancer [17], melanoma [19], prostate cancer [18], and lung cancer [15], but only a few studies has been done in the field of Head and Neck Squamous Cell Carcinoma (HNSCC). Mann et al. reported that proinflammatory cytokines including IL-1, -4, and -6 were detected in HNSCC [20] and Chen et al. found that the HNSCC patients showing high serum level of IL-1a, IL-6, IL-8, GM-CSF, and VEGF cytokines generally had a poor prognosis [14]. However the exact functional role or production mechanism of these proinflammatory cytokines in HNSCC has not been identified. In this study, we propose that the interaction between overexpressed functional P2X7R and NLRP3 components is crucial to proinflammatory cytokine production and to the survival and invasiveness of HNSCC.

\section{RESULTS}

\section{Over-expression of P2X7R in oral cancer tissue}

First, we examined head and neck cancer tissues collected from six different patients to measure levels of P2X7R expression. All of the samples were histologically diagnosed as squamous cell carcinoma (SCC). (Figure 1A) shows the representative Western blot analyses from three patients. P2X7R expression was upregulated compared to that of the normal tissues. (Figure 1B) shows a summarized result. The expression levels of P2X7R were significantly higher in the patient group than in the control group. $(P=0.0002, n=14)$

\section{Over-expression of inflammasome components in oral cancer tissue}

We also found significant upregulation of the mRNA levels of NLRP3, ASC, caspase- 1 , and IL-1 $\beta$ in the HNSCC mass (NLRP3; $P=0.0153$, Caspase-1; $P=0.0216$, IL-1 $\beta ; P=0.0087$, ASC; $P=0.0225, n=9)$ (Figure 2A, 2C). NLRP3 inflammasome activity was also determined by measuring the protein level of active caspase-1 p20 (20 kDa). As expected, active caspase-1 was robustly detected in HNSCC tissues, while it was rarely detected in normal tissues (Figure 2B). Although the mRNA levels of NLRP3 inflammasome components were generally elevated in HNSCC mass, the degree of its elevation was very different in each patient. We compared the various tumor properties and prognosis of each patient and found correlation(s) with degrees of NLRP3 inflammasome overexpression. Five of the nine HNSCC patients subjected to qPCR analysis consented to our review of their medical history chart and surgery report. We averaged the mRNA expression level fold changes of ASC, IL-1 $\beta$, Caspase-1, and NLRP3 for each patient, and aligned the results from low to high average fold change value. (Table 1) shows an association between patients' prognosis and tumor mass property and the expression level of P2X7R and NALP3 inflammasome. We found that the patient with lowest average value showed no recurrence, metastasis, and no specific post-operative problems. In contrast, patient No.5 at maximum average value showed an extremely bad prognosis with recurrence, multiple distant metastasis, inflammatory changes in Sternocleidomastoid muscle (SCM m.) post-surgery, and largest tumor size with deepest depth of invasion among the five patients. Patients number 2,3, and 4 showed either recurrence or metastasis but showed little differences in prognosis, tumor size, and depth of invasion.

\section{Functional upregulation of P2X7R and NLRP3 inflammasome components in $\mathrm{A} 253$ cells}

The over-expression of P2X7R and NLRP3 inflammasome components in cancer tissues was further observed through using two types of salivary gland epithelial cell lines: Human Salivary Gland (HSG) cells derived from the duct of human submandibular glands and A253 cells derived from the epidermoid carcinoma harvested from human submandibular glands. P2X7R and the components related to NLRP3 inflammasome were upregulated in the A253 cells compared to the HSG cells (Figure 3).

Before we examined the functional relationship between P2X7R and NLRP3 inflammasome, the cells were pretreated with LPS for priming. After the stimulation of HSG, A253, and THP-1 (human monocytic cell line) cells with $1 \mu \mathrm{g} / \mathrm{ml} \mathrm{LPS}$, the mRNA levels of inflammasome components including ASC, caspase-1, and NLRP3 were examined. THP-1 cells were used as a positive control group (Figure $3 \mathrm{~A}$ ). In both LPSprimed and unprimed HSG cells, the mRNA of NLRP3 inflammasome components was not detected. In contrast, in the A253 cells, expressions of ASC and procaspase-1 were increased. Intracellular pro-IL-1 $\beta$ was significantly increased in the primed A253 cells, but no mature IL-1 $\beta$ was detected, since there was no detectable caspase-1 p20. P2X7R, TLR4, and procaspase-1 were also expressed in HSG cells, but their expression levels were much less than those in the A253 cells, and no significant expressional change was observed after LPS stimulation. In contrast to the A253 cells, ASC expression was not detected in HSG cells at all. Although pro-IL-1 $\beta$ expression was slightly increased by LPS treatment in HSG cells, caspase- 1 p20 and mature IL-1 $\beta$ were not detected (Figure 3B). 

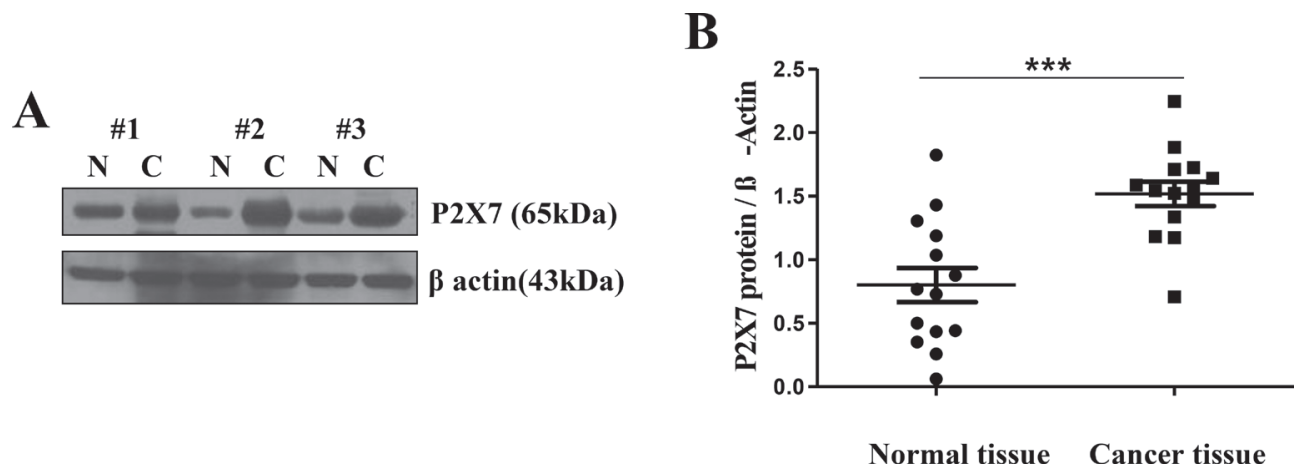

Figure 1: Over-expression of P2X7R in oral cancer tissue. (A) Excised HNSCC and normal tissues were collected from three different patients to assess the expression level of P2X7R by Western blot (Lanes 1, 3, 5: normal tissues; lanes 2, 4, 6: oral cancer tissues). (B) The expression levels of P2X7R were significantly higher in the HNSCC patient group than in the control group $(* * * P<0.001, n=14)$.

A
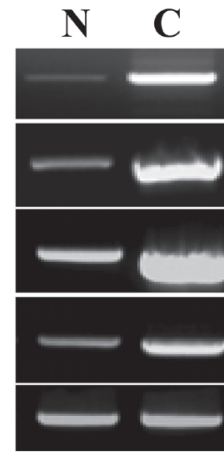

B

NALP3

Caspase1

IL-1ß

ASC

\section{GAPDH}
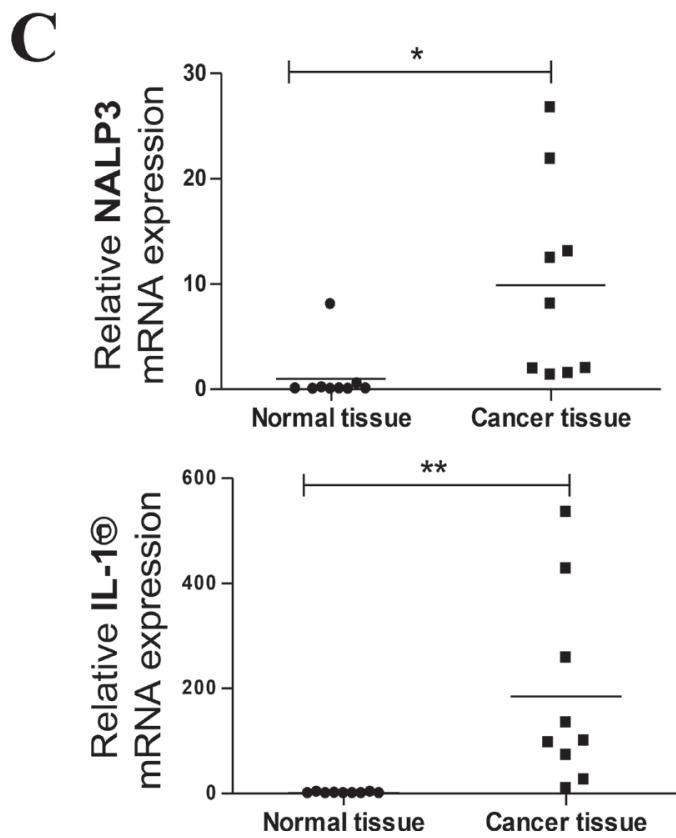
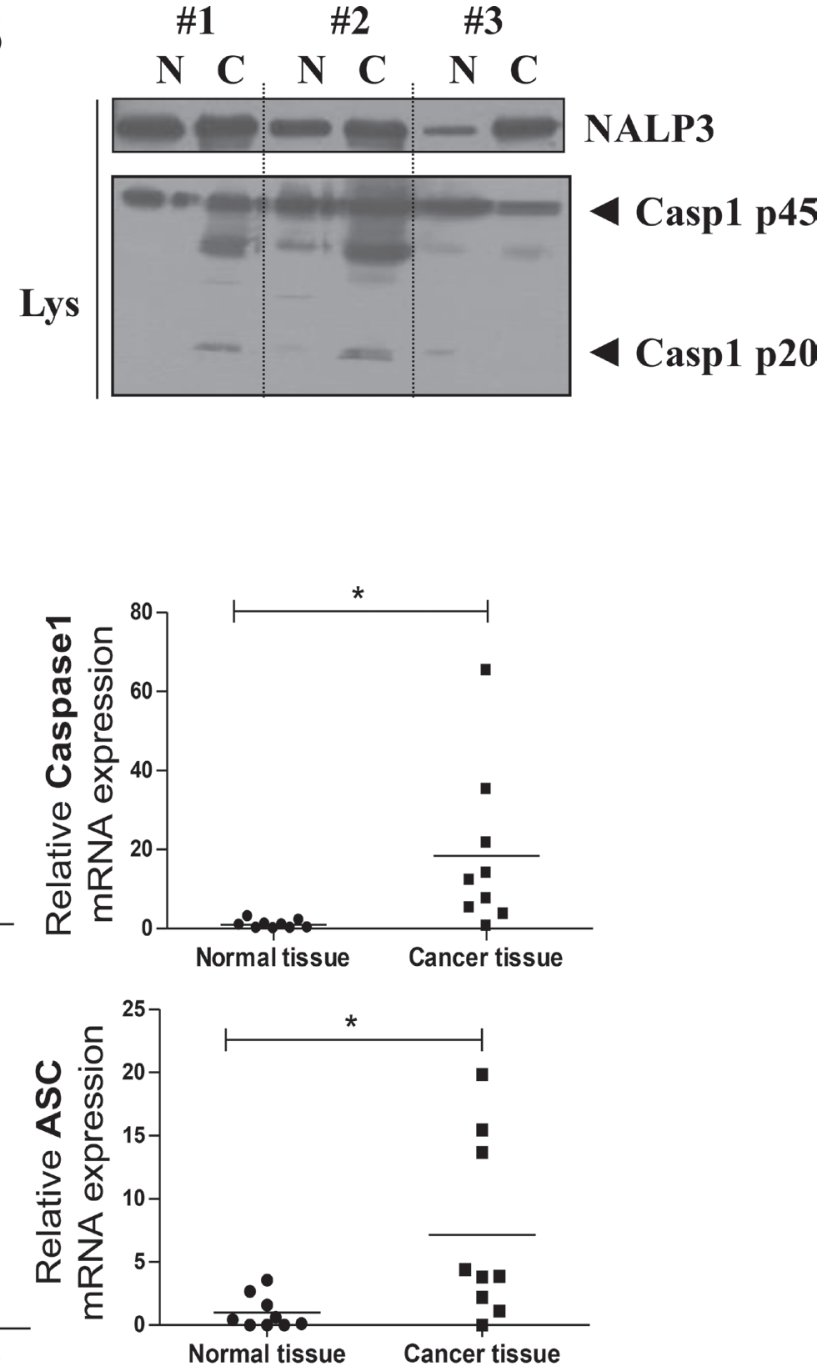

Figure 2: Over-expression of inflammasome components in oral cancer tissue. (A) mRNA expression of the inflammasome components NLRP3, caspase-1, and ASC and the inflammatory cytokines IL-1 $\beta$. GAPDH is shown as a loading control. (B) A representative Western blot of three normal human tissue $(\mathrm{N})$ and three HNSCC samples shows the protein expressions of NLRP3 protein, pro-caspase-1 (45 kDa), and activated caspase-1 p20 (20 kDa). (C) qPCR data collected from nine HNSCC patients' tumor and normal tissues. Raw data from normal tissues of each group was averaged and set as 1 , thus fold change of each individual sample based on this value was plotted $(n=9, * P<0.05, * * P<0.01)$. 
Table 1: Various tumor properties and prognosis of each patient and correlation(s) with degrees of NLRP3 inflammasome overexpression

\begin{tabular}{|c|c|c|c|c|c|c|c|c|c|c|c|}
\hline \multirow{2}{*}{$\begin{array}{l}\text { Patient } \\
\text { number }\end{array}$} & \multirow{2}{*}{$\begin{array}{l}\text { Patient age/ } \\
\text { sex }\end{array}$} & \multicolumn{4}{|c|}{$\begin{array}{l}\text { mRNA expression fold change (HNSCC/Normal } \\
\text { tissue) }\end{array}$} & \multirow{2}{*}{$\begin{array}{l}\text { Average fold } \\
\text { change }\end{array}$} & \multirow{2}{*}{ Recurrence } & \multirow{2}{*}{ Metastasis } & \multirow{2}{*}{$\begin{array}{l}\text { Tumor size } \\
\quad(\mathrm{cm} 3)\end{array}$} & \multirow{2}{*}{$\begin{array}{c}\text { Depth of } \\
\text { invasion } \\
\text { (cm) }\end{array}$} & \multirow{2}{*}{ Objective findings after surgery } \\
\hline & & ASC & IL-1b & Caspase1 & NLRP3 & & & & & & \\
\hline 1 & $75 / \mathrm{F}$ & 1.69872 & 0.267326 & 0.721025 & 9.765946 & 3.113254 & No & No & 17.64 & 2.1 & $\mathrm{~N} / \mathrm{S}$ \\
\hline 2 & $67 / \mathrm{F}$ & 7.434229 & 14.20622 & 1.605869 & 1.392034 & 6.159587 & No & $\begin{array}{c}\text { Yes } \\
(1 / 28 \mathrm{LN})\end{array}$ & 26.64 & 1.2 & $\mathrm{~N} / \mathrm{S}$ \\
\hline 3 & $60 / \mathrm{M}$ & 7.561513 & 33.04599 & 5.781747 & 1.72429 & 12.02839 & Yes & No & 7.92 & 1.5 & $\begin{array}{c}\text { Right neck level II recur } 1 \mathrm{Y} 2 \mathrm{M} \text { after surgery } \\
\text { No distant metastasis }\end{array}$ \\
\hline 4 & $58 / \mathrm{M}$ & 23.02545 & 77.49942 & 0.990481 & 12.26093 & 28.44407 & No & $\begin{array}{c}\text { Yes } \\
(2 / 33 \mathrm{LN})\end{array}$ & 7.392 & 1.2 & $\mathrm{~N} / \mathrm{S}$ \\
\hline 5 & $58 / \mathrm{M}$ & 368.354 & 16035.55 & 3516.315 & 21734.22 & 10413.61 & Yes & $\begin{array}{c}\text { Yes } \\
\text { (Multiple, } \\
\text { distant } \\
\text { metastasis) }\end{array}$ & 35.84 & 3.2 & $\begin{array}{c}\text { Recur } 1 \text { Y7M after surgery } \\
\text { Lt neck, mediastinum } \\
\text { Left SCM m. swelling } \\
\text { Inflammatory change } \\
\text { Metastatic lymph node, multiple: left level Ib, } \\
\text { Iia, III, IV }\end{array}$ \\
\hline
\end{tabular}

Averaged mRNA expression level fold changes of ASC, IL-1 $\beta$, Caspase-1, and NLRP3 for each patient is aligned from low to high average fold change value. History of recurrence and metastasis is analyzed, and tumor size $(\mathrm{cm} 3)$ and depth of invasion $(\mathrm{cm})$ recorded in pathophysiology lab reports and surgery reports are described. Post-surgery medical reports are collected, and any abnormal or significant postsurgery events are described as "objective findings after surgery". Five patients were analyzed.

However, when A253 cells were stimulated with ATP, all components of the NLRP3 inflammasome (including ASC, procaspase-1 (45kDa), and NLRP3) gradually increased in proportion to ATP concentration. Caspase-1 p20 became detectable after the priming step at ATP concentrations above $5 \mathrm{mM}$. Next, we examined whether LPS stimulation is required to activate the NLRP3 inflammasome via P2X7R activation. When A253 cells were stimulated with ATP alone, caspase-1 p20 was not detected, and no change in the expression levels of the P2X7R and NLRP3 components was observed by increasing ATP concentration. However, when A253 cells were stimulated with ATP after the LPS priming step, all components of the NLRP3 inflammasome (ASC,
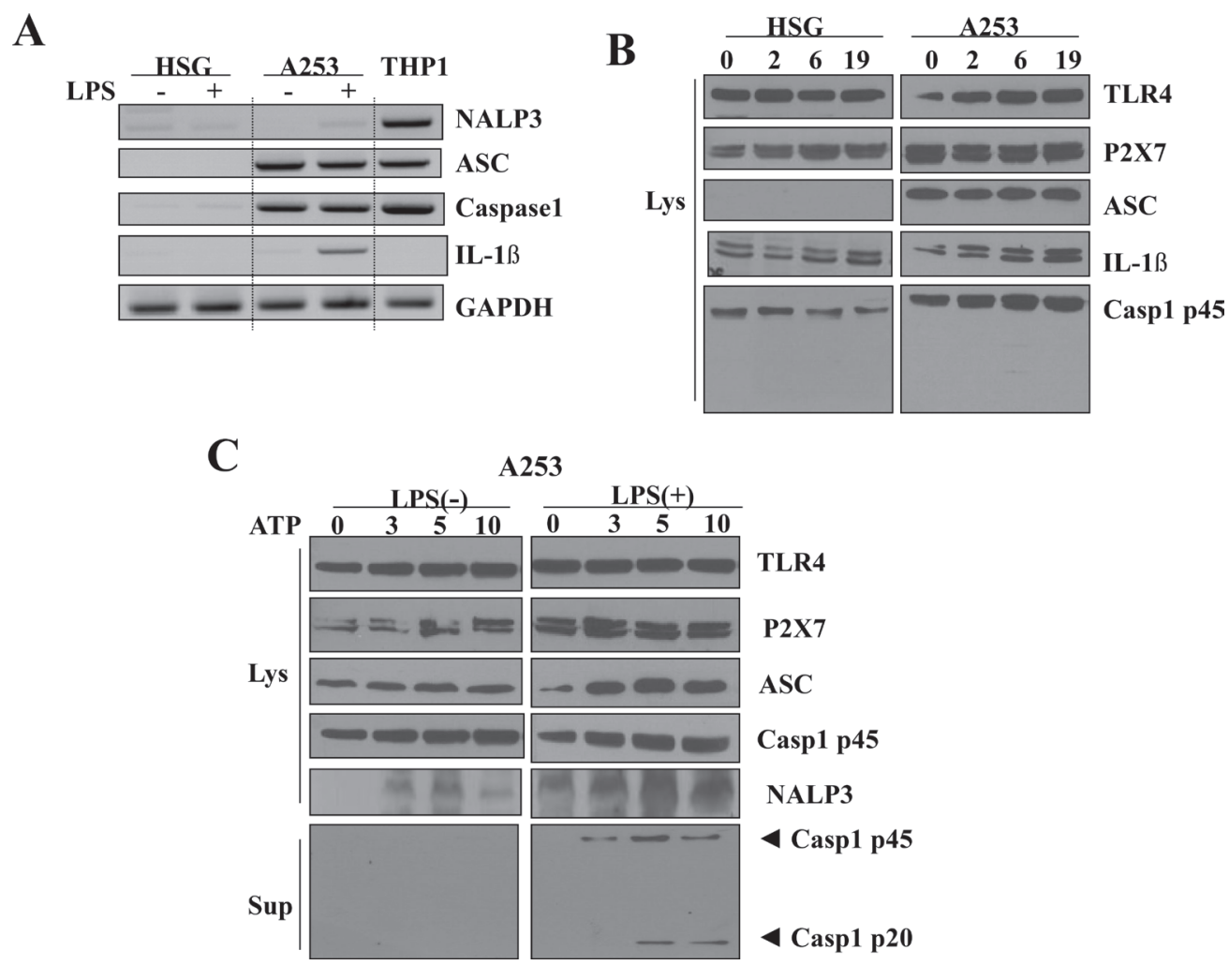

A253

TLR4

P2X7

ASC

Casp1 p45

NALP3

4 Casp1 p45

4 Casp1 p20

Figure 3: Upregulation of P2X7R and NLRP3 inflammasome components in A253 cells. (A) The mRNA expression of NLRP3 inflammasome components in A253 and HSG cells. THP-1 cells, a macrophage cell line, were used as a positive control. Cells were treated with LPS for priming. RT-PCR analysis shows detectable levels of mRNA coding for members of the NLRP3 inflammasome complex. Results shown are representative of 3-4 individual experiments. (B) Expression of NLRP3 inflammasome in HSG and A253 cells at $0,2,6$, and $19 \mathrm{~h}$ after stimulation with $1 \mu \mathrm{g} / \mathrm{ml}$ LPS. (C) NLRP3 inflammasome signaling is dispensable for ATP dose-dependent caspase-1 activation induced by LPS in A253 cells. 
procaspase-1 (45 kDa), and NLRP3) gradually increased in proportion to the ATP concentration, and caspase-1 p20 also became detectable at ATP concentrations above $5 \mathrm{mM}$ (Figure 3C).

\section{Role of P2X7R in the activation of NLRP3 inflammasome}

We further examined whether the NLRP3 inflammasome is activated by a specific $\mathrm{P} 2 \mathrm{X} 7 \mathrm{R}$ agonist in the presence or the absence of the antagonist. When primed A253 cells were treated with $0.3 \mathrm{mM}$ 3-O-benzoylbenzoicacid-derivatized ATP analogue (BzATP; a specific agonist of P2X7R), the expressions of P2X7R itself, NLRP3, and pro-IL-1 $\beta$ were significantly increased to similar levels as when treated with $5 \mathrm{mM}$ ATP concentrations. Active-form IL-1 $(17 \mathrm{kDa})$ and caspase-1 p20 were also detected when primed A532 cells were treated with $0.3 \mathrm{mM}$ BzATP or $5 \mathrm{mM}$ ATP (Figure 4A). We obtained a similar result with another P2X7R agonist, nigericin. As the concentration of nigericin increased from $5 \mu \mathrm{M}$ to $20 \mu \mathrm{M}$, ASC expression levels also gradually increased. Furthermore, active caspase-1 (p20) became detectable at the nigericin concentration of $10 \mu \mathrm{M}$ and increased as the nigericin concentration rose to $20 \mu \mathrm{M}$ (Figure 4B). Next, we tested oATP, a specific blocker of P2X7R. Compared to the groups treated only with ATP, the groups treated with both oATP and ATP showed decreased expression of NLRP3, but still showed higher degrees of expression than that of control groups (Figure 4C). The decrease in the protein level of active caspase- 1 p20, a key enzyme for IL-1 $\beta$ maturation, affected by oATP clearly indicates that NLRP3 inflammasome activation is mediated by P2X7R (Figure 4C).

\section{Activity of P2X7R and NLRP3 inflammasome is closely related to the survival and invasiveness of A253 cells}

We next examined the biological roles of P2X7R and NLRP3 inflammasome in A253 cells. Antagonist (oATP; $20 \mu \mathrm{M}$ ) and agonist (BzATP; $0.3 \mathrm{mM}$ ) of P2X7R and specific inhibitor of NLRP3 inflammasome (MCC950; $10 \mu \mathrm{M})$ were used independently or in combination. MCC950 was developed by Rebecca C et al. and is known to specifically inhibit both canonical and noncanonical NALRP3 activation by blocking NLRP3induced ASC oligomerization [21]. MCC950 does not block AIM2, NLRC4, TLR pathways nor the K+ efflux, $\mathrm{Ca} 2+$ efflux, or NLRP3-ASC interaction, which makes it ideal to independently examine NLRP 3 and P2X7 in LPS-primed cells [21]. A253 cells were LPS-primed for $19 \mathrm{hrs}$ and then treated with oATP $(1 \mathrm{mM})$, BzATP (0.3 mM), Ac-YVAD-cmk (caspase-1 inhibitor; $30 \mu \mathrm{g} / \mathrm{ml}$ ), MCC950 (NLRP3 inflammasome inhibitor; $10 \mu \mathrm{M}$ ), or in combination of one another for $24 \mathrm{hrs}$. CCK 8 cell viability assay results showed significant decrease in cellular respiratory rate only when P2X7R and NLRP3 inflammasome were both inhibited by oATP and MCC950 in A253 cells $(P=0.0117, n=6)$ (Figure 5A). However, there was no significant reduction of cell viability when $30 \mu \mathrm{g} / \mathrm{ml}$ of Ac-YVAD-cmk, a caspase-1 inhibitor, was treated with oATP/BzATP on A253 cells (Figure 5A). Significant increase in viability over control group was not observed in all groups (Figure 5A). This decrease in the cell viability by MCC $950+$ oATP treatment was not observed in normal cells including HSG and primary cultured human fibroblast cells from a section of biopsied sample histologically diagnosed as normal (Figure 5B). To find out whether this decreased viability rate in A253 cells was due to cell death or declined proliferative capacity we performed Propidium iodide(PI)/Calcein AM dead or live assay. Significantly increased infiltration of PI dye and decreased metabolized Calcein AM signals in MCC950+oATP treated A253 cells $(P=0.0006, n=6)$ indicated that the inhibition of both P2X7R and NLRP3 inflammasome induced actual cell death (Figure 5C, 5D). Next we examined the role of P2X7R and NLRP3 inflammasome in invasiveness of A253 cells. To minimize the cell death induced by MCC $950+$ oATP during invasion process, $24 \mathrm{hr}$-drug-treated A253 cells were trypsinized and an equal number of viable cells was seeded to upper chamber matrigel filled with pure DMEM. 24hrs later invaded cells were stained with crystal violet and manually counted in 20X magnified view. Invasiveness of A253 cells were significantly reduced by blocking either P2X7R or NLRP3 inflammasome (oATP; $P=0.0162$, MCC950; $P=0.0323, n=6$ ) (Figure 5E, 5F). However the reduction of invasiveness became more evident when both P2X7R and NLRP3 inflammasome were inhibited (MCC950+oATP; $P=0.0033, n=6$ ) (Figure 5E, 5F).

\section{DISCUSSION}

We describe here that P2X7R and NLRP3 inflammasome, over-expressed in HNSCC, are potentially related to the survival and invasiveness of HNSCC cells in vitro, and further, to the prognosis of HNSCC patients.

We found that both P2X7R and NLRP3 inflammasome component expression were upregulated in cancer tissues compared to normal tissues. Active caspase-1 p20 was detected in every HNSCC cancer tissue sample, suggesting that IL- $\beta$ also has to be cleaved to become activated. Since active caspase-1 was detected in HNSCC samples, it is evident that HNSCC can produce active IL-1 $\beta$ by itself. However, in vitro experiments revealed that a very small amount of active IL-1 $\beta$ was released extracellularly from A253 (epithelial cells) compared to immune cells such as THP1 cell. Therefore, we suspected that the release of active IL-1 $\beta$ from HNSCC cells was due to pyroptosis, which could be induced by Gasdermin D activation via active 
caspase-11 or caspase -1 , rather than general exocytosis mechanism [22]. Chen et al. also reported that IL-1 $\beta$ was not detected in patients' serum [14]. Although limited amounts of released active IL-1 $\beta$ cannot affect distant areas around tumor mass, it may have affected tumor mass itself as an autocrine signal or microenvironment to enhance its malignancy. In tumor immunology, IL-1 is associated with cancer progression and development [6]. IL-1 and -6 are usually produced by tumor-associated macrophages such as the M2 macrophage. However, our findings suggest that the stimulation of over-expressed P2X7R on HNSCC or epithelial cells produces active IL$1 \beta$ via the NLRP3 inflammasome pathway independent of the surrounding tumor-associated macrophages. Several studies have reported that the tumor microenvironment contains high concentrations of IL-1, and that it promotes the angiogenesis and proliferation of tumor cells via indirect stimulation of neighboring normal cells to produce angiogenic and metastatic factors [16]. In fact, when we matched degree of mRNA expression data of NLRP3, ASC, IL-1 $\beta$, and caspase-1 with each patient's medical records, increased tendencies to recur and metastasize were observed with increased expression levels. Similar phenomena have been reported in studies on the relationship between IL-1 and prognosis of solid tumors including breast, colon, lung, and melanoma [16]. Due to limited number of patients it is difficult to statistically prove this hypothesis in our study, but further clinical studies may reveal more detailed correlations between NLRP3 inflammasome pathway and HNSCC malignancy.
We also confirmed that ATP-mediated activation of $\mathrm{P} 2 \mathrm{X} 7 \mathrm{R}$ is capable of inducing inflammasome activation in the HNSCC A253 cell line. In unstimulated HSG cells, NLRP3 components were barely detected at either mRNA or protein level. However, in the A253 cells, these components were constitutively upregulated without any stimulation. P2X7R expression and its activity were also significantly elevated in A253 cells compared to HSG cells. This result is consistent with our previous study reporting that $\mathrm{CpG}$ islands of $\mathrm{P} 2 \mathrm{X} 7 \mathrm{R}$ gene are naturally hypermethylated in HSG cells [23]. The specific stimulation of P2X7R by BzATP activated the NLRP3 inflammasome pathway in A253 cells, but interestingly, neither P2X7R nor NLRP3 inflammasome activation was detected in HSG cells even after ATP or BzATP stimulation following the priming step. It seems that the P2X7R expressed in HSG cells are in a somewhat "inactive" state unresponsive to the agonists. Our previous study also showed that A P2X7R-induced $\mathrm{Ca}^{2+}$ increase was not detected in HSG cells even after treatment with high concentration of ATP or BzATP [23]. Therefore, it is highly likely that the NLRP3 inflammasome pathway is generally silenced in normal epithelial cells; however, when they become cancerous, the NLRP3 inflammasome becomes activated by the increased expression and activity of P2X7R.

Therefore, we suspected that targeting P2X7R and NLRP3 inflammasome may mitigate HNSCC malignancy without harming normal tissues surrounding them. Consistent with this premise, significant cell death was observed only when P2X7R and NLRP3 inflammasome
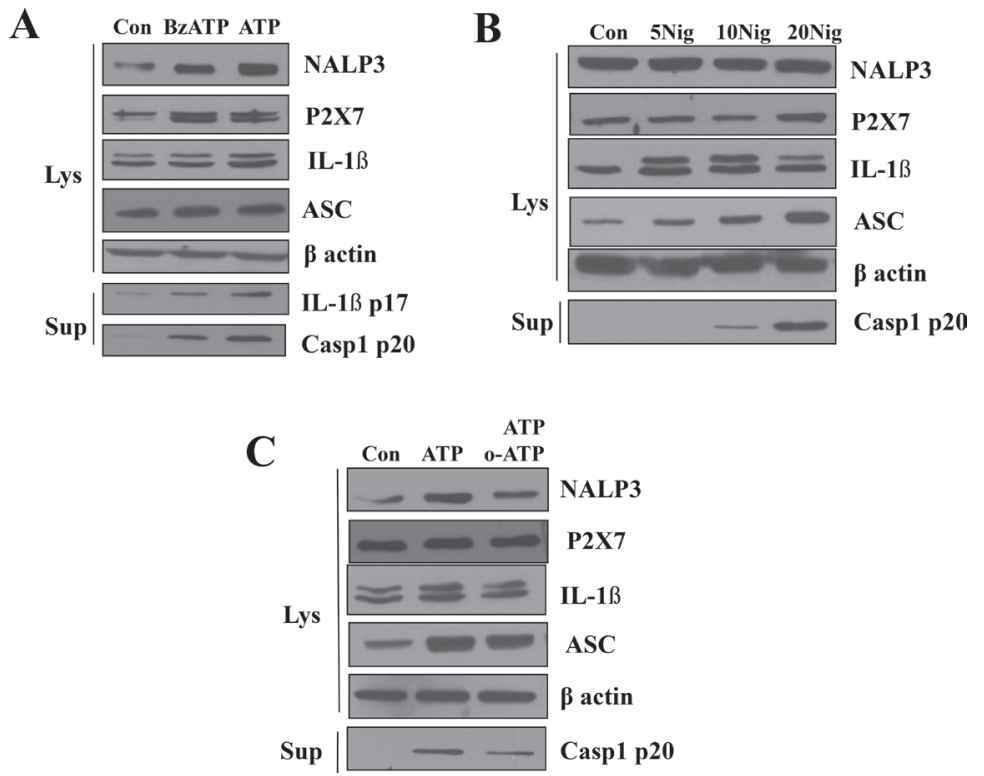

Figure 4: Role of P2X7R in the activation of NLRP3 inflammasome. (A) LPS-primed A253 cells were stimulated with 0.3 $\mathrm{mM}$ 2,3-O-(4-benzoyl-benzoyl)ATP (BzATP) for $3 \mathrm{~h}$ except for ATP that was added $30 \mathrm{~min}$ before the end of the experiment. Treatment with $5 \mathrm{mM}$ ATP or $0.3 \mathrm{mM}$ BzATP induced the release of caspase-1. (B) A253 cells were stimulated for $6 \mathrm{~h}$ with the indicated amounts (per $\mathrm{ml}$ ) of nigericin. The range of nigericin concentrations was from $5 \mu \mathrm{M}$ to $20 \mu \mathrm{M}$. Results shown are representative of 3-4 individual experiments (C) ATP or oxATP induced the release of caspase-1 in LPS-primed A253 cells. 

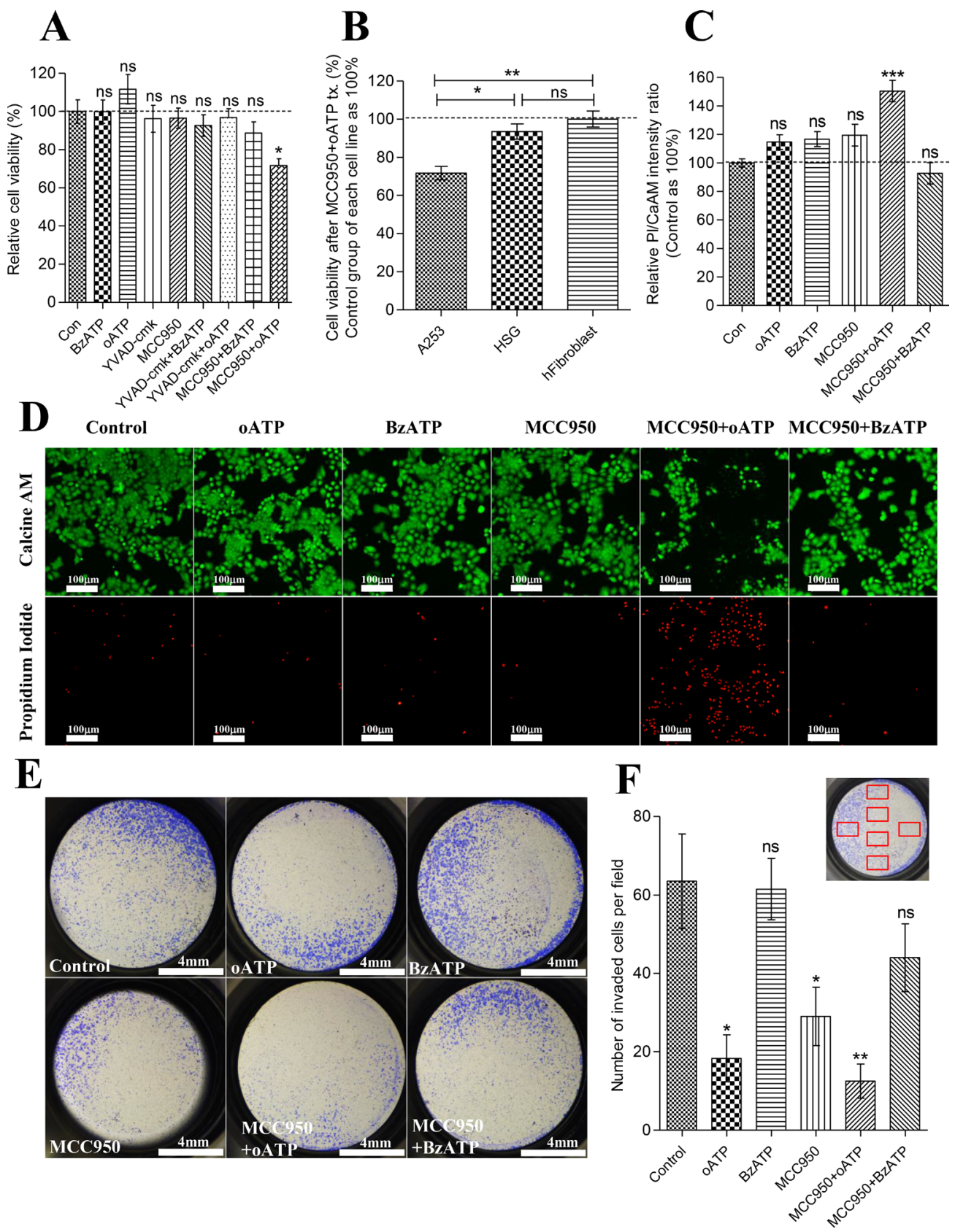

Figure 5: Activity of P2X7R and NLRP3 inflammasome is closely related to the survival and invasiveness of A253 cells. (A) CCK-8 cell viability assay of LPS-primed A253 cells treated with oATP $(1 \mu \mathrm{M})$, BzATP $(0.3 \mathrm{mM})$, caspase-1 inhibitor (Ac-YVAD-cmk; $30 \mu \mathrm{g} / \mathrm{ml})$, MCC950 $(10 \mu \mathrm{M})$, or in combination of one another for 24hrs. Absorbance values at $450 \mathrm{~nm}$ of control group were averaged and set as $100 \%$. Data are expressed as the mean \pm SEM of $n=6\left({ }^{*} P=<0.05\right)$. (B) CCK-8 cell viability assay of LPS-primed A253, HSG, and primary cultured human fibroblast cells treated with combination of oATP $(1 \mathrm{mM})+\mathrm{MCC} 950(10 \mu \mathrm{M})$. Absorbance values at $450 \mathrm{~nm}$ of each cell line's control group were averaged and set as $100 \%$. Data are expressed as the mean \pm SEM of $n=6\left(* P=<0.05,{ }^{* *} P<0.01\right)$. (C) Relative fluorescence intensity ratio of Propodium Iodide/Calcein AM. LPS-primed A253 cells were treated with oATP (1 mM), BzATP $(0.3 \mathrm{mM})$, MCC950 $(10 \mu \mathrm{M})$, or in combination of one another for $24 \mathrm{hrs}$. FL intensity ratios of PI/CaAM of control group were averaged and set as $100 \%$. Data are expressed as the mean \pm SEM of $n=6\left({ }^{*} P=<0.05,{ }^{* *} P<0.01\right)$. (D) Epifluorescence image of PI/CaAM. LPS-primed A253 cells were treated with oATP $(1 \mathrm{mM})$, BzATP $(0.3 \mathrm{mM})$, MCC950 $(10 \mu \mathrm{M})$, or in combination of one another for $24 \mathrm{hrs}$. FL images of PI channel were equally enhanced by increasing $40 \%$ brightness and $40 \%$ contrast. FL images of CaAM are unmodified images. (E) Matrigel invasion assay result. LPS-primed A253 cells were treated with oATP $(1 \mathrm{mM})$, BzATP $(0.3 \mathrm{mM})$, MCC950 $(10 \mu \mathrm{M})$, or in combination for 24 hrs and trypsinized. 50000 viable cells were reseeded in each insert of the invasion chamber. 24 hrs later, invaded cells were fixed and stained with $1 \%$ crystal violet, and images of entire well were captured. 3 independent experiments were carried out. (F) Number of invaded cells per 20× magnified field was manually counted. Six different area of insert were selected and captured by Inverted microscope with 20X magnification. Selected areas are described in the graph as red squares. Data are expressed as the mean \pm SEM of $n=6\left({ }^{*} P=<0.05,{ }^{* *} P<0.01\right)$. 
were both inhibited by oATP and MCC950, a specific inhibitor of NLRP3 inflammasome. However treatment of a caspase- 1 inhibitor with oATP or BzATP did not induce significant cell death. This indicates that caspase-1 or its final product, IL-1 $\beta$, is not crucial for HNSCC cell survival in isolated conditions without a surrounding tumor microenvironment. In addition the MCC950+oATP combination did not induce cell death in normal cells which neither overexpress P2X7R nor NLRP3 inflammasome components. This result shows a possibility that the MCC950+oATP combination can be therapeutically used to specifically kill HNSCC without harming surrounding normal cells. Invasiveness of A253 was also largely suppressed by P2X7R and NLRP3 inflammasome blockers. We found that an inhibition of either P2X7R or NLRP3 inflammasome was enough to reduce invasiveness of A253, although reduction of invasiveness became more evident when both were blocked.

Based on our results, it seems survival of P2X7R/ NLRP3 inflammasome-over-expressing cells is largely dependent on the caspase-1 independent NLRP3 inflammasome pathway. Several studies have reported that NLRP3 and ASC have caspase-1-independent function. ASC by itself, independent of caspase-1, can induce autoimmune diseases including arthritis and encephalitis [24, 25]. Wang et al. reported that NLRP3 and ASC caspase-1-independently regulate Transforming growth factor- $\beta 1$ (TGF- $\beta 1$ ) in renal tubular epithelial cells [26]. Considering that the TGF- $\beta 1$ promotes cancer invasion and metastasis via enhancement of EMT related genes, it is possible that this mechanism is behind reduced invasion by P2X7R and NLRP3 inhibition. However, only a few mechanism studies have been conducted to explain caspase-1-independent NLRP3/ASC activities. Further investigations will be required to unveil the mechanism of reduced invasion and viability caused by simultaneous inhibition of P2X7R and NLRP3.

In this study, we suggested that P2X7R and NLRP3 inflammasome are over-expressed in HNSCC and that the degree of expressional level may represent prognosis of patients. To our knowledge, this is the first report that HNSCC can produce active IL-1 $\beta$ via P2X7/NLRP3 inflammasome pathways, and also the first trial to reduce HNSCC survival and invasiveness by blocking P2X7R/ NLRP3 inflammasome. These findings on the relationship between P2XR and NLRP3 inflammasome in HNSCC may contribute to the development of novel therapeutic approaches or diagnostic markers predicting the prognosis and degree of HNSCC malignancy.

\section{MATERIALS AND METHODS}

\section{Reagents}

Lipopolysaccharide (LPS; Escherichia coli 0111:B4), ATP, and oxidized ATP (oxATP) were obtained from Sigma (St. Louis, MO, USA), and nigericin was purchased from InvivoGen (San Diego, CA, USA). AcYVAD-cmk and MCC950(CP-456773 sodium salt) were purchased from Sigma (St. Louis, MO, USA). Cell Counting Kit-8 (CCK-8) was purchased from Dojindo (Japan). Calcein AM iwas purchased from Invitrogen (Carlsbad, CA, USA) and $1 \mathrm{mg} / \mathrm{ml}$ Propidium iodide solution was purchased from Sigma (St. Louis, MO, USA). 1\% Crystal violet solution was purchased from Sigma (St. Louis, MO, USA). NLRP3 antibodies and secondary anti-sheep antibody conjugated to horseradish peroxidase (HRP) were purchased from R\&D Systems (Minneapolis, MN, USA). Toll-like receptor 4 (TLR4), P2X7, ASC, IL-1 $\beta$, and caspase-1 donkey anti-rabbit IgGHRP were purchased from Santa Cruz Biotechnology (Santa Cruz, CA, USA).

\section{Cell culture}

HSG cells isolated from human submandibular ducts and A253 cells derived from human squamous carcinoma in submandibular glands were cultured in Dulbecco's Modified Eagle's Medium (Welgene, Daegu, South Korea) supplemented with $10 \%$ fetal bovine serum (Welgene) and $1 \%$ penicillin/streptomycin (Gibco, Carlsbad, CA, USA) at $37^{\circ} \mathrm{C}$ in a humidified $5 \% \mathrm{CO}_{2}$ incubator. Media change was done three times a week and sub-cultured when cells were approximately $80 \%$ confluent. $0.25 \%$ trypsin $/ 1.0 \mathrm{mM}$ ethylenediaminetetraacetic acid (Welgene) was used to detach cells from the culture dish. Primary cultured normal human fibroblast cells were obtained from biopsy sample of a patient. Normal tissue was submerged in $70 \%$ EtOH for 2 min for the sterilization and washed twice with PBS. Normal tissue was minced in HBSS and transferred to cell culture dish containing DMEM supplemented with $10 \% \mathrm{FBS}$ and $1 \%$ penicillin/streptomycin, and incubated for 7 days. At the day 7 media and unattached cells were completely removed. Attached cells were split into four $100 \mathrm{~mm}$ dishes and continuously subcultured or cryopreserved. Media was changed twice a week.

\section{RT-PCR}

Total RNA from normal submandibular gland tissues and oral squamous cell carcinoma tissues were extracted using Trizol (Invitrogen, Carlsbad, CA, USA) according to the manufacturer's protocol. The extracted total RNA concentration was quantified using a NanoDrop ${ }^{\circledR}$ ND-2000 spectrophotometer (NanoDrop Technologies, Wilmington, DE, USA). Reverse transcriptase (Invitrogen) was used with $1 \mu \mathrm{g}$ of total RNA. Polymerase chain reaction (PCR) with specific primers was performed using $1 \mu \mathrm{l}$ of cDNA.

The primer sets were as follows: NLRP3: forward 5'-ATG GCA AGC ACC CGC TGC-3' and reverse 5'-GCT GTC TTC CTG GCA TAT CAC AG-3'; ASC: forward 5'GCC AAG CCA GGC CTG CAC-3' and reverse 5'-GCT 
CCG CTC CAG GTC CTC-3'; caspase-1: forward 5'GAA ACA AAA GTC GGC AGA GA-3' and reverse 5'TGG GAA GAG GTA GAA ACA TC-3'; IL-1 $\beta$ : forward 5'-ATG GCA GAA GTA CCT AAG CTC GC-3' and reverse 5'-ACA CAA ATT GCA TGG TGA AGT CAG TT-3'; and GAPDH: forward 5'-TTC ACC ACC ATG GAG AAG GC-3' and reverse 5'-TCA TGA CCA CAG TCC ATG CC-3'. PCR conditions were as follows: 35 cycles of denaturation at $95^{\circ} \mathrm{C}$ for $55 \mathrm{~s}$, annealing at $55^{\circ} \mathrm{C}$ for $30 \mathrm{~s}$, and extension at $72^{\circ} \mathrm{C}$ for $55 \mathrm{~s}$; and a final step at $72^{\circ} \mathrm{C}$ for $10 \mathrm{~min}$. Products from RT-PCR reactions were sequenced to confirm their expression. The PCR products were confirmed by ethidium bromide staining after $1.5 \%$ agarose gel electrophoresis.

\section{Quantitative real-time PCR}

Total RNA was isolated from Oral squamous cell carcinoma tissues and normal submandibular gland tissues using the Trizol reagent (Invitrogen), and then used in Superscript III reverse transcriptase reaction (Invitrogen) for cDNA synthesize with and oligo-(dT) primers according to the manufacturer's protocol. For quantitative Real-time PCRs were performed with SYBR green premix buffer (Applied Bio-Systems, Foster City, CA, USA) and an ABI Prism 7500 sequence detector (Applied Biosystems), and relative expression levels were determined after normalization to the threshold cycle (CT) values for GAPDH.

The gene-specific primers were as follows: for NLRP3: forward 5'- TCC TCA GCA GCA ACC AGA AG $-3^{\prime}$ and reverse 5'- GCT TCA GTC CCA CAC ACA GA3'; ASC: forward 5'- TCC TCA GTC GGC AGC CAA G $-3^{\prime}$ and reverse 5'-TCA GGA CCT TCC CGT ACA GA -3'; Caspase-1: forward 5'- CAA GGT CCT GAA GGA GAA GAG A -3' and reverse 5'- TGT TCA GCA CCC TTG TCT GT-3'; IL-1 $\beta$ : forward 5'- AGT ACC TGA GCT CGC CAG T-3' and reverse 5'- CTG GAA GGA GCA CTT CAT CTG T-3'; and GAPDH: forward 5'- GTC AAG GCT GAG AAC GGG AA -3' and reverse 5'- TGG ACT CCA CGA CGT ACT CA - 3'.

\section{Human tissue}

Oral squamous cell carcinoma tissues and normal submandibular gland tissues were obtained from the patients. Biopsied tissues were stored in $4{ }^{\circ} \mathrm{C}$ normal HEPES buffer right after the surgical excision for the further processing. Gland tissues obtained from the same patients were confirmed as non-cancerous by pathology department of SNU dental hospital and thus used as normal or control groups. All ethical guidelines and consent forms were approved by Institutional Review Board of Seoul National University Dental Hospital (CRI11023G).

\section{Western blot assay}

After the three-times of phosphate-buffered saline washes cells were lysed by RIPA buffer supplemented with $1 \%$ protease inhibitor cocktail (GenDEPOT, Katy, TX, USA). Protein concentration was measured using the bicinchoninic acid protein assay kit (Pierce Biotechnology, Rockford, IL), and bovine serum albumin was used to generate protein concentration standard curve. Proteins were separated on $10 \%$ sodium dodecyl sulfate polyacrylamide gel electrophoresis (Bio-Rad, Hercules, CA, USA), and this was followed by electrotransfer onto nitrocellulose membranes (Whatman, Dassel, Germany). The membranes were blocked with $10 \%$ non-fat milk (Seoul-milk, Seoul, Korea) in Tris-buffered saline with Tween for $1 \mathrm{~h}$, and the blots were then incubated overnight at $4^{\circ} \mathrm{C}$ with a primary anti-NLRP3 antibody (R\&D Systems), anti-P2X7 antibody (Santa Cruz Biotechnology), anti-IL-1 $\beta$ antibody (Santa Cruz Biotechnology), anti-ASC antibody (Santa Cruz Biotechnology), anticaspase-1 antibody (Santa Cruz Biotechnology), antiTLR4 antibody (Santa Cruz Biotechnology), and antiactin antibody (Santa Cruz Biotechnology) and were then incubated with HRP-conjugated secondary antibody (Santa Cruz Biotechnology). The bands were developed by an enhanced electrochemiluminescence detection system (Thermo Scientific, Waltham, MA, USA). The bindings of the specific antibodies were visualized using Agfa film (Agfa, Mortsel, Belgium).

\section{CCK-8 cell viability assay}

Cells were seeded on 96-well plate with 5000cell/ well density and incubated in $37^{\circ} \mathrm{C}$ in a humidified $5 \% \mathrm{CO}_{2}$ incubator for $12 \mathrm{hrs}$. Then, media is changed to DMEM containing $1 \mu \mathrm{g} / \mathrm{ml} \mathrm{LPS}$, and cells were incubated for another $19 \mathrm{hrs}$ for priming. After the priming step each group $(n=6)$ of cells were treated with oATP $(1 \mathrm{mM})$, BzATP (0.3 mM), Ac-YVAD-cmk (30 $\mu \mathrm{g} / \mathrm{ml})$, MCC950 (10 $\mu \mathrm{M})$, or in combination. $24 \mathrm{hrs}$ after the drug treatment media was changed to non-phenol red DMEM containing 5\% CCK8 stock solution. $1 \mathrm{hr}$ later absorbance was measured at $450 \mathrm{~nm}$ in Synergy 2 microplate reader (Biotek).

\section{Propidium iodide/calcein AM live dead assay}

A253 Cells were seeded on two black walled 96well plate (SPL, Korea) with 5000cell/well density and incubated in $37^{\circ} \mathrm{C}$ in a humidified $5 \% \mathrm{CO}_{2}$ incubator for $12 \mathrm{hrs}$. Then, media is changed to DMEM containing $1 \mu \mathrm{g} / \mathrm{ml} \mathrm{LPS}$, and cells were incubated for another $19 \mathrm{hrs}$ for priming. After the priming step each group $(n=4$ for imaging $/ n=6$ for FL measurement) of cells was treated with oATP (1 mM), BzATP (0.3 mM), Ac-YVAD-cmk $(30 \mu \mathrm{g} / \mathrm{ml}), \mathrm{MCC} 950(10 \mu \mathrm{M})$, or in combination. $24 \mathrm{hrs}$ 
after the drug treatment media was changed to non-phenol red DMEM containing $3 \mu \mathrm{M}$ Propidium iodide and $3 \mu \mathrm{M}$ Calcein AM. After the $30 \mathrm{~min}$ of incubation images were obtained by Digital Inverted Fluorescence Microscope (Nikon) with $20 \times$ magnification. Another plate was subjected to Synergy 2 microplate reader (Biotek) to measure fluorescence intensity of PI (Ex: 540/25 Em: 590/20) and Calcein AM (Ex: 485/20 Em:528/20). PI fluorescence values were divided by Calcein AM fluorescence values to get the relative ratio of cell death FL signal out of viable cell signal.

\section{Matrigel invasion assay}

A253 cells were seeded on six $100 \mathrm{~mm}$ cell culture dish with $1 \times 10^{6}$ cells/dish density and incubated in $37^{\circ} \mathrm{C}$ in a humidified 5\% $\mathrm{CO}_{2}$ incubator for $12 \mathrm{hrs}$. Then, media is changed to DMEM containing $1 \mu \mathrm{g} / \mathrm{ml}$ LPS, and cells were incubated for another $19 \mathrm{hrs}$ for priming. After the priming step each group of cells was treated with oATP $(1 \mathrm{mM})$, BzATP $(0.3 \mathrm{mM})$, Ac-YVAD-cmk $(30 \mu \mathrm{g} / \mathrm{ml})$, MCC950 $(10 \mu \mathrm{M})$, or in combination. $24 \mathrm{hrs}$ after the drug treatment cells were washed and detached with $0.5 \%$ Trypsin and dispersed in DMEM and then transferred to upper chamber of pre-humidified 24-well Corning BioCoat Matrigel Invasion Chamber (\#354480 $8.0 \mu \mathrm{m}$ PET membrane). Lower chamber was filled with 750 ul of $10 \%$ FBS containing DMEM to attract cells. After the $24 \mathrm{hrs}$ of incubation each insert was washed twice with PBS and un-migrated cells were wiped away by using cotton sticks. Migrated cells were fixed with $4 \%$ Paraformaldehyde (PFA) for $10 \mathrm{~min}$ and stained with 1\% Crystal violet solution for $30 \mathrm{~min}$. Inserts were washed twice with tap water to remove remaining Crystal violet solution and completely dried up for $2 \mathrm{hrs}$ in drying oven. Images of invaded cells were captured by Leica S6D stereo microscope with $2.5 \times$ magnification. Number of invaded cells was manually counted based on the images obtained at six different locations per group using Digital Inverted Fluorescence Microscope (Nikon) with 20× magnification.

\section{ACKNOWLEDGMENTS AND FUNDING}

This work was supported by an International Research \& Development Program of the National Research Foundation of Korea (NRF) funded by Republic of Korea (No. 2016K2A9A2A06004840) and a National Research Foundation of Korea Grant through the Oromaxillofacial Dysfunction Research Center for the Elderly (No. 2016-929358) at Seoul National University in Korea.

\section{CONFLICTS OF INTEREST}

The authors declare no conflicts of interest.

\section{REFERENCES}

1. Surprenant A, Rassendren F, Kawashima E, North RA, Buell G. The cytolytic P2Z receptor for extracellular ATP identified as a P2X receptor (P2X7). Science. 1996; 272:735-738.

2. Adinolfi E, Raffaghello L, Giuliani AL, Cavazzini L, Capece M, Chiozzi P, Bianchi G, Kroemer G, Pistoia V, Di Virgilio F. Expression of P2X7 receptor increases in vivo tumor growth. Cancer Res. 2012; 72:2957-2969.

3. Deli T, Varga N, Adam A, Kenessey I, Raso E, Puskas LG, Tovari J, Fodor J, Feher M, Szigeti GP, Csernoch L, Timar J. Functional genomics of calcium channels in human melanoma cells. Int J Cancer. 2007; 121:55-65.

4. Raffaghello L, Chiozzi P, Falzoni S, Di Virgilio F, Pistoia V. The P2X7 receptor sustains the growth of human neuroblastoma cells through a substance P-dependent mechanism. Cancer Res. 2006; 66:907-914.

5. Zhang XJ, Zheng GG, Ma XT, Yang YH, Li G, Rao Q, Nie K, $\mathrm{Wu} \mathrm{KF}$. Expression of P2X7 in human hematopoietic cell lines and leukemia patients. Leuk Res. 2004; 28:1313-1322.

6. Mantovani A, Romero P, Palucka AK, Marincola FM. Tumour immunity: effector response to tumour and role of the microenvironment. Lancet. 2008; 371:771-783.

7. Mariathasan S, Weiss DS, Newton K, McBride J, O'Rourke K, Roose-Girma M, Lee WP, Weinrauch Y, Monack DM, Dixit VM. Cryopyrin activates the inflammasome in response to toxins and ATP. Nature. 2006; 440:228-232.

8. Compan V, Baroja-Mazo A, Lopez-Castejon G, Gomez AI, Martinez CM, Angosto D, Montero MT, Herranz AS, Bazan E, Reimers D, Mulero V, Pelegrin P. Cell volume regulation modulates NLRP3 inflammasome activation. Immunity. 2012; 37:487-500.

9. Petrilli V, Papin S, Dostert C, Mayor A, Martinon F, Tschopp J. Activation of the NALP3 inflammasome is triggered by low intracellular potassium concentration. Cell Death Differ. 2007; 14:1583-1589.

10. Baldini C, Rossi C, Ferro F, Santini E, Seccia V, Donati V, Solini A. The P2X7 receptor-inflammasome complex has a role in modulating the inflammatory response in primary Sjogren's syndrome. J Intern Med. 2013; 274:480-489.

11. Kim EH, Park MJ, Park S, Lee ES. Increased expression of the NLRP3 inflammasome components in patients with Behcet's disease. J Inflamm (Lond). 2015; 12:41.

12. Lee HM, Kim JJ, Kim HJ, Shong M, Ku BJ, Jo EK. Upregulated NLRP3 inflammasome activation in patients with type 2 diabetes. Diabetes. 2013; 62:194-204.

13. Choulaki C, Papadaki G, Repa A, Kampouraki E, Kambas K, Ritis K, Bertsias G, Boumpas DT, Sidiropoulos P. Enhanced activity of NLRP3 inflammasome in peripheral blood cells of patients with active rheumatoid arthritis. Arthritis Res Ther. 2015; 17:257. 
14. Chen Z, Malhotra PS, Thomas GR, Ondrey FG, Duffey DC, Smith CW, Enamorado I, Yeh NT, Kroog GS, Rudy S, McCullagh L, Mousa S, Quezado M, et al. Expression of proinflammatory and proangiogenic cytokines in patients with head and neck cancer. Clin Cancer Res. 1999; 5:1369-1379.

15. Kong H, Wang Y, Zeng X, Wang Z, Wang H, Xie W. Differential expression of inflammasomes in lung cancer cell lines and tissues. Tumour Biol. 2015; 36:7501-7513.

16. Lewis AM, Varghese $\mathrm{S}, \mathrm{Xu} \mathrm{H}$, Alexander HR. Interleukin-1 and cancer progression: the emerging role of interleukin-1 receptor antagonist as a novel therapeutic agent in cancer treatment. J Transl Med. 2006; 4:48.

17. Li Y, Wang L, Pappan L, Galliher-Beckley A, Shi J. IL1 beta promotes stemness and invasiveness of colon cancer cells through Zeb1 activation. Mol Cancer. 2012; 11:87.

18. Qiu Y, Li WH, Zhang HQ, Liu Y, Tian XX, Fang WG. P2X7 mediates ATP-driven invasiveness in prostate cancer cells. PLoS One. 2014; 9:e114371.

19. Verma D, Bivik C, Farahani E, Synnerstad I, Fredrikson M, Enerback C, Rosdahl I, Soderkvist P. Inflammasome polymorphisms confer susceptibility to sporadic malignant melanoma. Pigment Cell Melanoma Res. 2012; 25:506-513.

20. Mann EA, Spiro JD, Chen LL, Kreutzer DL. Cytokine expression by head and neck squamous cell carcinomas. Am J Surg. 1992; 164:567-573.

21. Coll RC, Robertson AA, Chae JJ, Higgins SC, MunozPlanillo R, Inserra MC, Vetter I, Dungan LS, Monks BG, Stutz A,
Croker DE, Butler MS, Haneklaus M, et al. A small-molecule inhibitor of the NLRP3 inflammasome for the treatment of inflammatory diseases. Nat Med. 2015; 21:248-255.

22. Kayagaki N, Stowe IB, Lee BL, O’Rourke K, Anderson K, Warming S, Cuellar T, Haley B, Roose-Girma M, Phung QT, Liu PS, Lill JR, Li H, et al. Caspase-11 cleaves gasdermin $\mathrm{D}$ for non-canonical inflammasome signalling. Nature. 2015; 526:666-671.

23. Shin YH, Kim M, Kim N, Choi SK, Namkoong E, Choi SY, Lee JH, Cha S, Park K. Epigenetic alteration of the purinergic type 7 receptor in salivary epithelial cells. Biochem Biophys Res Commun. 2015; 466:704-710.

24. Shaw PJ, Lukens JR, Burns S, Chi H, McGargill MA, Kanneganti TD. Cutting edge: critical role for PYCARD/ ASC in the development of experimental autoimmune encephalomyelitis. J Immunol. 2010; 184:4610-4614.

25. Kolly L, Karababa M, Joosten LA, Narayan S, Salvi R, Petrilli V, Tschopp J, van den Berg WB, So AK, Busso N. Inflammatory role of ASC in antigen-induced arthritis is independent of caspase-1, NALP-3, and IPAF. J Immunol. 2009; 183:4003-4012.

26. Wang W, Wang X, Chun J, Vilaysane A, Clark S, French G, Bracey NA, Trpkov K, Bonni S, Duff HJ, Beck PL, Muruve DA. Inflammasome-independent NLRP3 augments TGF-beta signaling in kidney epithelium. J Immunol. 2013; 190:1239-1249. 